\title{
Analysis of Near Infra Red (NIR) Impact as the Control Process of a Palm Oil Mill and Refinery Plant for Environmental Sustainability
}

\section{Lidya Elisabeth Simanjuntak, Tri Edhi Budhi Soesilo, Herdis Herdiansyah*}

School of Environmental Science, Universitas Indonesia, Salemba Campus, Jakarta, Indonesia

Received: 5 April 2019

Accepted: 10 December 2019

\begin{abstract}
The development of the plantation sector in Indonesia is overgrowing. Industry, aside from being an indicator of potential economic activities and employment equity, impacts the environment. Processing of crude palm oil (CPO) into its derivatives through several stages of the process, sampling took in each stage of the process and analysis of samples by conventional methods that use chemicals that produce hazardous waste. The use of near infrared (NIR) in the samples does not require chemical substances, thereby reducing the amount of hazardous waste and thus causing less negative environmental impact compared to other analytical methods. Since the NIR analysis method does not require chemical substances, the timing of analysis becomes faster and more efficient, albeit at relatively high equipment prices. The purpose of this research is to analyze the effectiveness of NIR used as the process control. This study uses a statistical method to see the accuracy and precision. The result of this study show that the NIR analysis can shorten the analysis time compared to the primary standard method (extraction). With the NIR method, time taken from preparing the samples to data analysis obtained is \pm 5 minutes, while with the standard method (extraction) it takes 9.5 hours. This research will be expected as a literature review or reference in the assessment of the effectiveness of the use of NIR in reducing waste at various CPO refinery factories in Indonesia. It is expected that the result of this study is utilized as a stakeholder reference for NIR usage as the control process for environmental sustainability.
\end{abstract}

Keywords: crude palm oil, environmental sustainability, hazardous waste, near infrared analysis

*e-mail: herdis@ui.ac.id 


\section{Introduction}

Agriculture is one sectors that contributes to economic activities in Indonesia. It contributed about $15.34 \%$ to the gross domestic product (GDP) in 2010 and ranks second after the processing industry sector. At the time of the economic crisis, the agriculture sector was strong enough to face economic shocks and be reliable in the recovery of the national economy.

One of the subsectors of potency is the estate subsector. Although the contribution of the plantation subsector to the formation of gross domestic product, it has not been too significant at $2.11 \%$ in 2010 - ranking third in the agricultural sector after the crop and fishery subsectors. However, according to the Central Bureau of Statistics of the Republic of Indonesia [1], this subsector is the supplier of raw materials for the industrial sector, labour absorber and foreign exchange earner.

Some of the existing plantation commodities in Indonesia are coconut, rubber, oil palm, sugar cane, pepper, coffee, tobacco and cocoa. Plantation commodities that have a crucial role in the country's economic activity are palm oil since becoming the world's largest oil exporter and producer [1].

Palm oil economic activity contributes significantly to Indonesia's growing economy. In connection with this, the government launched a master program for also accelerating the expansion of economic development (MP3EI) in 2011-2015. In this program, Sumatra is proposed as a centre for palm oil production and processing [2].

Product quality control for processing determines iodine value (IV), free fatty acid (FFA), and deterioration of bleaching index (DOBI). Iodine value (IV) is a measure of the total number of unsaturated double bonds present in fats and oils, which can be determinated by carrying out iodometric titration, which uses several chemicals such as the Cyclohexane Wijs solution, glacial acetic acid and potassium iodide solution. The material is included in the category of hazardous and toxic substances (B3) [3]. The use of hazardous and toxic chemicals is considered to have a negative impact on the environment - especially if the waste is not handled properly. According to Government Regulation No. 74/2001 on The Management of Hazardous and Toxic Materials [3], every person conducting hazardous and toxic materials (B3) management activities shall be obliged to prevent the occurrence of pollution and damage to the environment.

In this research, the authors offer alternative methods where the IV analysis is done using NIR spectroscopy. NIR is performed on the principle of molecular vibration [4]. The analysis does not include the use of chemicals, thereby reducing the amount of hazardous waste, making the NIR method cause less negative environmental impact compared to other analytical methods. Although the NIR method has a great potential to be applied because of its advantages, there is still a lack of research that addresses the effect of NIR use in process control - especially its application in refinery companies. The authors expect that the use of NIR will contribute to environmental sustainability.

This research will be expected to be the consideration of stakeholders and management of refinery companies throughout Indonesia to use NIR in the control process. The objective of this study is to analyze the accuracy and precision comparison between the use of NIR and iodometric titration. The authors expect that this research can act as a reference in handling industrial waste to achieve environmental sustainability and as a reference for the use of NIRs as process control. The authors also expected that the result of this research is utilized as a reference for the refinery companies in waste management and policy-making process. This paper is organized in the following main structure: introduction, theoretical background, method, results and discussion, and conclusions.

\section{Theoretical Background}

All data in this study based on statistical parameters used by experts in the field of analytical chemistry. The statistical parameters used in IV analysis by iodometry and NIR are a test of yield significance. The initial data analysis is based on a measure of accuracy that meets the test requirements. Equations 1 and 2 can be used:

$$
\mathrm{SD}=\sqrt{\frac{\sum_{\mathrm{i}=0}^{\mathrm{n}}\left(\mathrm{x}_{\mathrm{i}}-\overline{\mathrm{x}}\right)^{2}}{\mathrm{n}-1}}
$$

SD: standard deviation

$\Sigma$ : the sum of the squares of the difference in the i-th test with the average repetition of the test

$x_{i}$ : i-th test result

$\mathrm{x}$ : average repeat test results

$\mathrm{n}$ : number of test loops

$$
\% \operatorname{RSD}=\frac{\mathrm{SD}}{\overline{\mathrm{x}}} \times 100 \%
$$

RSD: relative standard deviation

SD: standard deviation

$\overline{\mathrm{x}}$ : average repetition of test results

Using the t-test statistical approach or $\mathrm{F}$ test to determine precision significance, the test value of test result $<t$ table value, or test value $F$ test cal $<$ value $F$ table, then Ho is accepted while $\mathrm{Ha}$ is rejected. If the test value test $>$ t table value, or test value $F$ cal $>$ Ftable value, then Ho is rejected, Ha accepted. Where:

- Ho: Test results for tests using NIR has no difference.

- Ha: The test results for tests using NIR are different with an iodometric method.

Verify whether the test results use new chemicals and expired chemicals are t-tested according to Equation 3: 


$$
\mathrm{t}=\frac{\left|\overline{\mathrm{x}}_{\mathrm{i}-\overline{\mathrm{x}}_{2} \mid}\right|}{\mathrm{s}} \sqrt{\frac{\mathrm{n}_{1} \mathrm{n}_{2}}{\mathrm{n}_{1}+\mathrm{n}_{2}}}
$$

$\overline{\mathrm{x}}_{\mathrm{i}-} \overline{\mathrm{x}}_{2}$ : difference between expired chemicals and new chemicals

$\mathrm{s}$ : standard deviation testing (assuming that s1 and s2 are the same)

$\mathrm{n}$ : number of tests/repetitions

If the value of $t<t$ table, then the null hypothesis is proved and the difference between both is considered meaningless. If the standard deviation (s) of the two tests are completely different, then a variance test or F-test can be used using Equation 4.

$$
\mathrm{F}=\frac{\mathrm{S}_{1}^{2}}{\mathrm{~S}_{2}^{2}}
$$

The smaller standard deviation ( $\mathrm{s}$ ) value is placed as a divisor so that the value of $F>1$. If the result of $F$ count is $<F$ table, then the values of the two tests are considered not significantly different.

The presentation of data will be displayed in tabular form. The substance of data presentation is based on the comparison between the value of test result parameters using NIR and iodometry in the laboratory.

\section{Method}

The method used is quantitative and qualitative, as described in Fig. 1. It is combined with literature review, observation, and analysis of the relationship of variables in the study [5]. The researcher limits the scope of the research object to be sampled to carry out the research. The population referred to in this study is sampled in controlling process in palm oil mill and refinery plant.

Primary data obtained by conventional analysis is used in this research. Then the secondary data obtained from the NIR analysis will be reordered on the primary data. The research stages were followed by researchers to obtain primary data.

\section{Results and Discussion}

NIR spectroscopy is based on a multivariate model in which spectral data correlates with the analyzing features, which provides several significant advantages because NIR spectroscopy does not require solvents or reagents, thus avoiding massive costs, as well as being environmentally friendly. Besides, NIR spectroscopy is a fast, non-destructive, and potentially multi-parameter method. Vibration techniques such as NIR spectroscopy can measure without sample preparation first. This technique can be used faster and more cost-effectively. This technique is very easy to use for a sustainable industry. Measurements are made based on results that will be mathematically and statistically calibrated to extract the information obtained [6-7].

Since the development of spectroscopic technology using NIR (1100-2500 nm) wavelengths in the early 1960 s, many areas of life have been touched by this technology, most notably its use for livestock, mainly animal feed [8-9]. The wavelengths of NIR spectroscopy range from about $800 \mathrm{~nm}$ to $2500 \mathrm{~m}$ and do not need sample preparation [10]. NIR spectroscopy is a non-

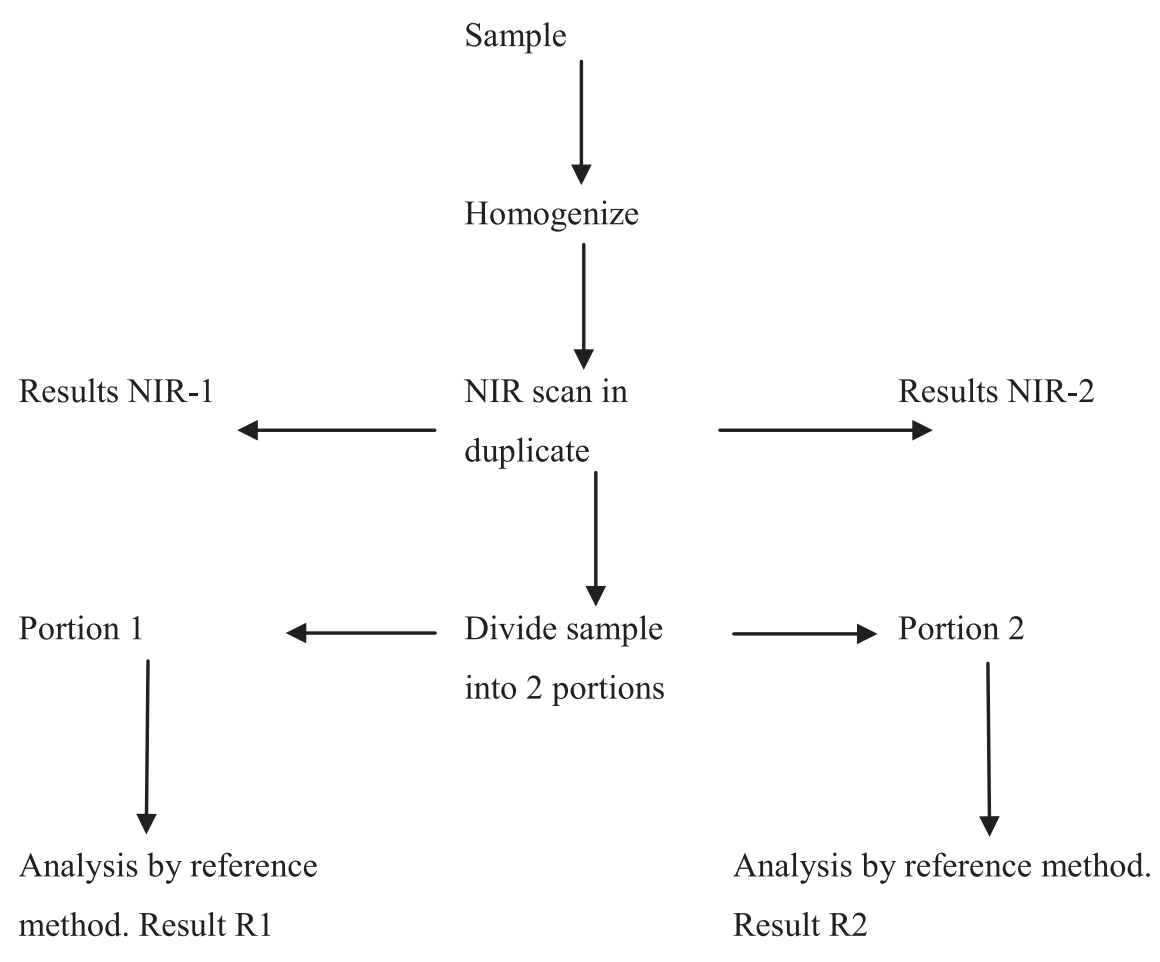

Fig. 1. Experimental flow chart. 
destructive method that is not only fast but also easy to use $[3,7]$. Merely the principle of this technology is based on the existence of differences in the characterization of material absorbance with chemical bond when receiving light waves on the spectrum. The acquired spectrum contains not only material sample information but also provides background information and noise [11-13]. This state is then calculated concerning the condition of the material when through conventional analysis such as chemical analysis/wet analysis using the chemometric concept, which is one of the statistical methods. This process is known as the calibration process; once calibration is completed, the prediction of the material properties according to the wet analysis can be made without having to do the same analysis again. This concept is also generally the analysis using this technology done without initial preparation [14-15].

\section{Application of NIR Apparatus in Quality Analysis at Palm Oil Mill}

In 1983 process control was implemented using NIR, where in this instrument there were 7 filters designed for online process control applications [3]. Before 1980, process control based on NIR spectroscopy was not reported frequently. Furthermore, in addition to other constituents, ethanol content is accurately measured in beer. Laboratory applications are recommended to extend in-line process control in breweries for fermentation monitoring and dilution control after high bureaucratic manufacturing. There is a development on online methods using NIR analysis, and this is expected to be one of the essential applications for future NIR use in the food industry [16].

NIR spectroscopy studies were reviewed to monitor the processing of wheat products [17-18]. In the food industry, NIR spectroscopy can provide information on chemical and physical changes in bread dough. Implementation of online NIRs has been used in sugarcane factories to improve performance [19]. In the development of cane sugar, parameters that are controlled (such as fiber, brix value, ash, and polarization) can be controlled.

Currently, the role of instrumentation in quality analysis is necessary - especially for quality control during production. Instruments can help laboratory analysts/technicians get data faster, require no elaborate preparation, and no material or solvent is needed so that it is safer for the analyst and the environment [20-21]. The instrument that has been most widely used as a tool for rapid analysis is NIR spectrophotometry, which uses broadband light-emitting diodes; incandescent light bulbs or quartz halogen light bulbs; a detector, such as a silicon-based charge coupled device (CCD) or indium gallium arsenide $(\mathrm{InGaA})$ and lead sulphide $(\mathrm{PbS})$, depending on the range of wavelengths to be measured; and a dispersion element, such as a prism or diffraction grating, to allow the intensity at different wavelengths to be recorded [22].

This NIR tool has also been designed for both liquid and solid samples and even a combination of both, and without damage to the sample [23]. NIR will interpret the samples on varying levels by displaying different spectra of color and different absorbance values $[15,24]$.

Fig. 2 shows the spectra scan for sample press fiber. Fig. 2 shows the overtone for each specific bond with a certain wavelength and the molecular vibrations area at 1,100-1,650 nm.

Fig. 3 shows the scatter plot for oil content in the Decanter sample, which will pass through the decanter where the function of the decanter is to separate the sludge into a heavy phase and solid light phase. The oil content was analyzed by NIR by titration method, which obtained a 0.999 slope with standard error

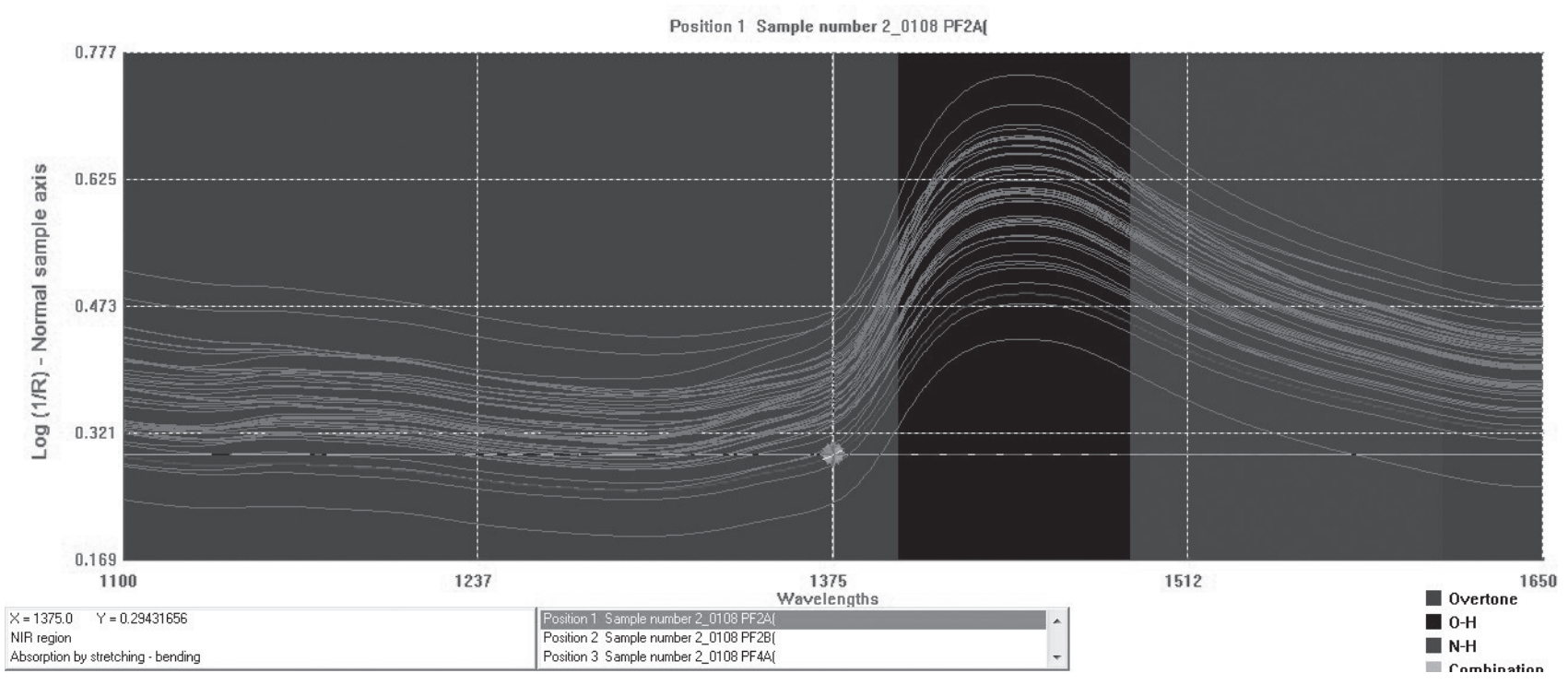

Fig. 2. Spectra scan press fibre. 


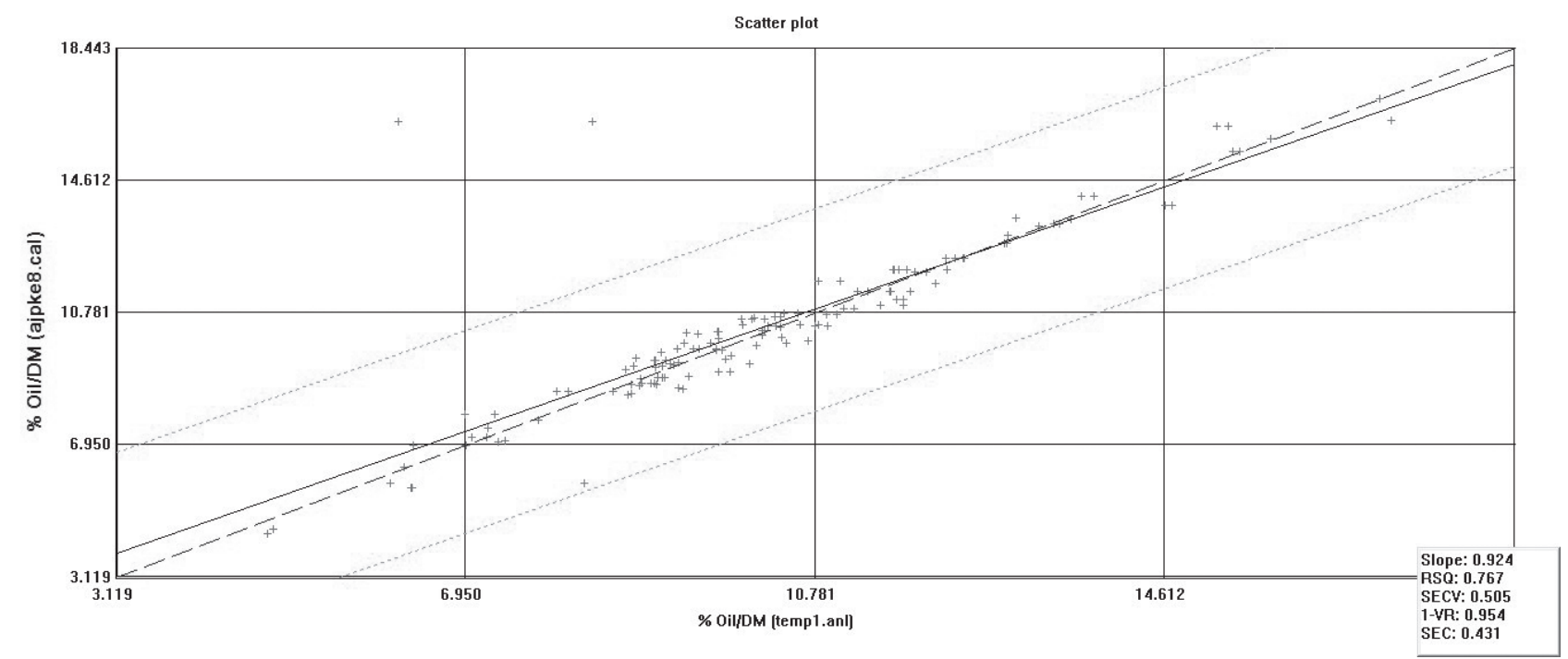

Fig. 3. Scatter plot, oil content decanter.

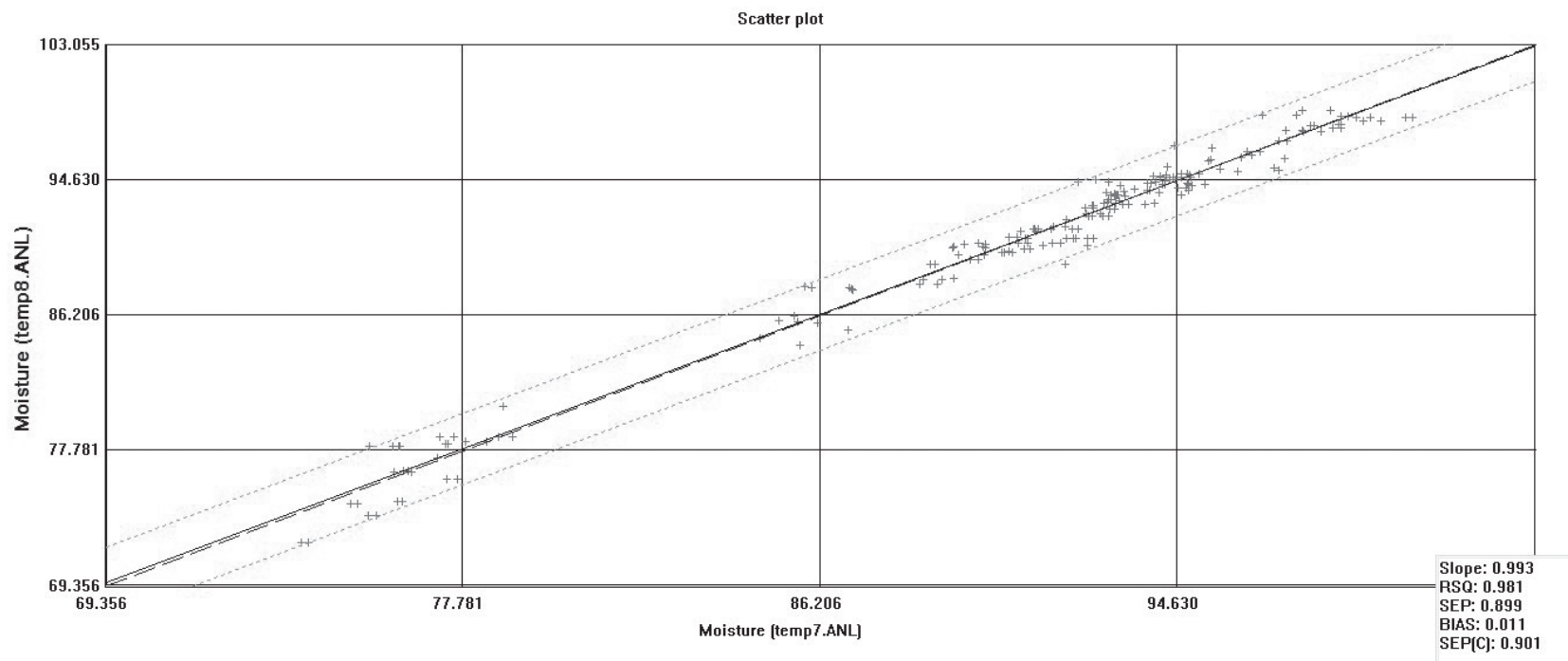

Fig. 4. Scatter plot moisture content decanter.

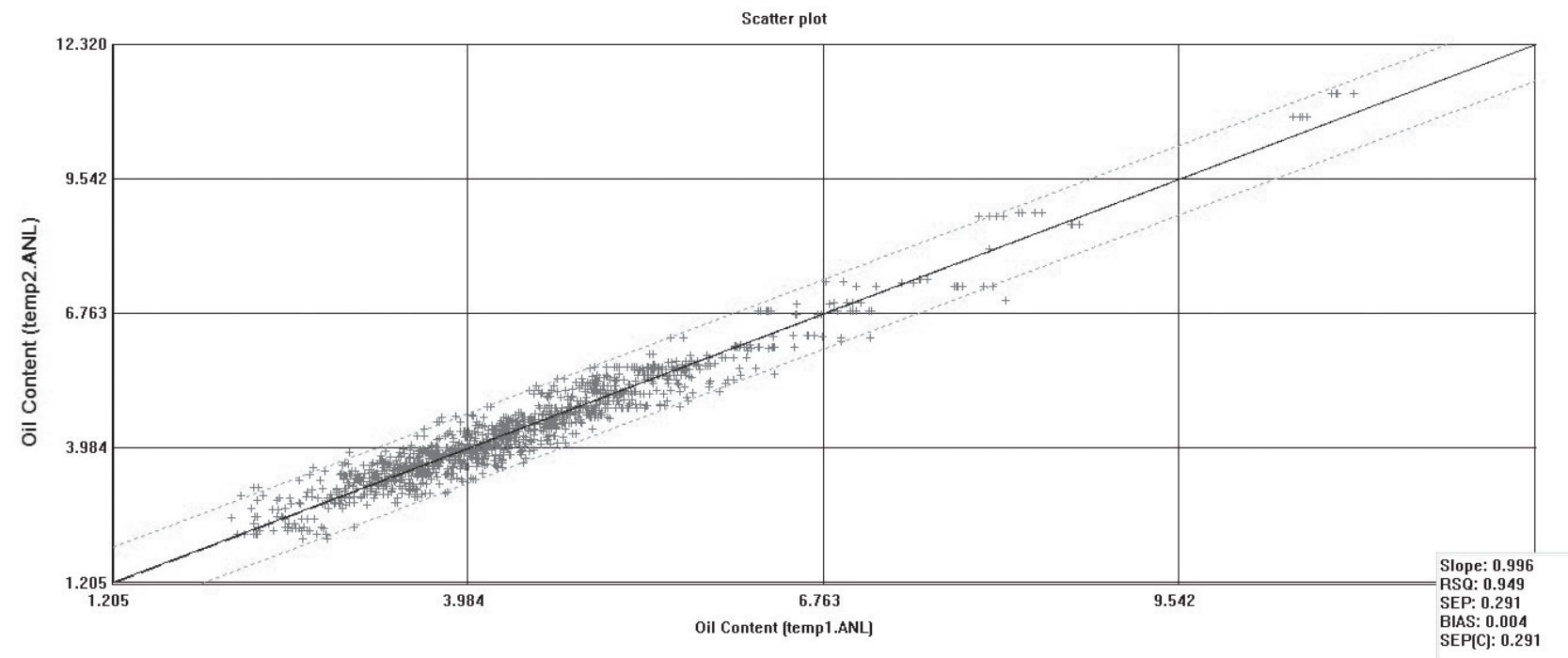

Fig. 5. Scatter plot oil content press fibre. 


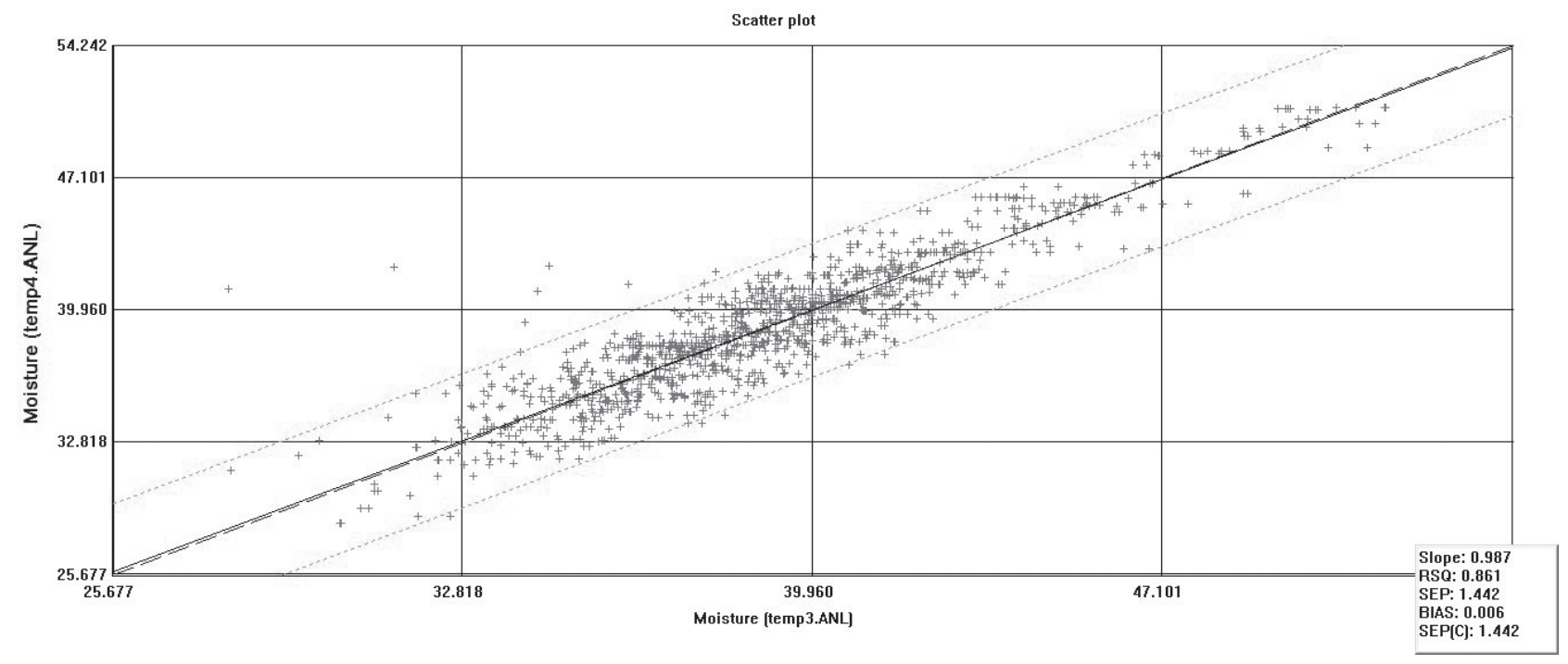

Fig. 6. Scatter plot moisture content press fibre.

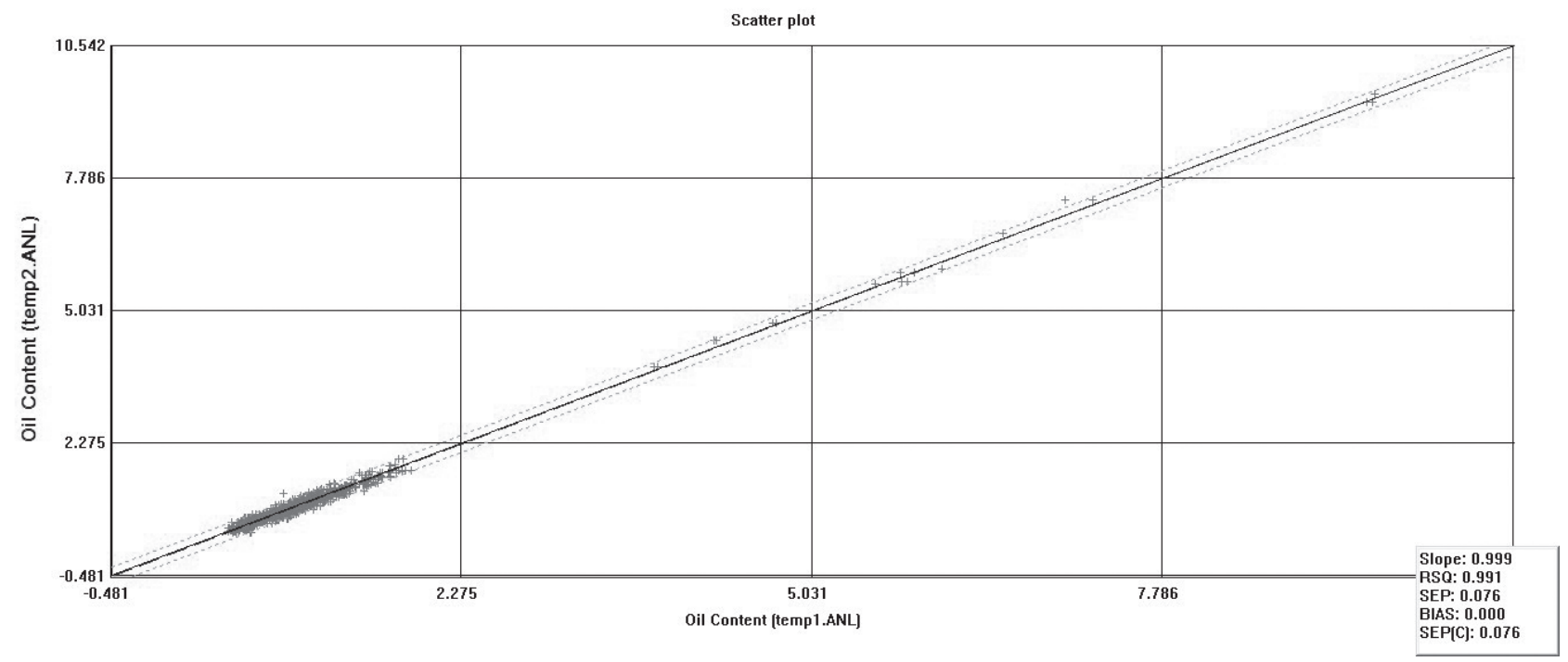

Fig. 7. Scatter plot oil content press POME.

cross validation 0.306 with the number of population 231 (numbers are coefficient and index without units). Calibration produces a good slope where the resulting error is also within statistical tolerance limits. This result can also be used to see whether the performance of the decanter engine is optimum or not.

Fig. 4 is a scatter plot of water content in the decanter sample where it obtained 0.993 slope and standard error of cross prediction 0.899 (numbers are coefficient and index without units). The population number is 225 .

Fresh fruit bunches (FFB) processed in the palm oil mill produced two type of products: crude palm oil (CPO) and palm kernels. The palm oil milling process consists of various stages that include sterilization of the FFB, stripping, pressing, clarification and purification of the crude oil. Beside two main products, the mill also generates pressed fibre [25]. Fig. 5 shows the scatter of oil content in the press fiber where the slope obtained is 0.996 with standard prediction error 0.291 (numbers are coefficient and index without units) with a population number of 1,635. The number of samples used is representative enough so that the resulting calibration is robust.

Near Infra-Red can measure moisture based on the reference and absorbance of the light by the sample. The amount of light absorbed will be directly proportional to moisture. So that as high as the light absorbed, the higher the water content in the sample. In Fig. 6, we can see the scatter plot of water content in the fiber press sample where the slope obtained is 0.987 and the prediction error standard is 1.442 (numbers are coefficient and index without units) with number of population 1,683. The slope generated quite well but the resulting error is quite large (more than 0.5 ). 


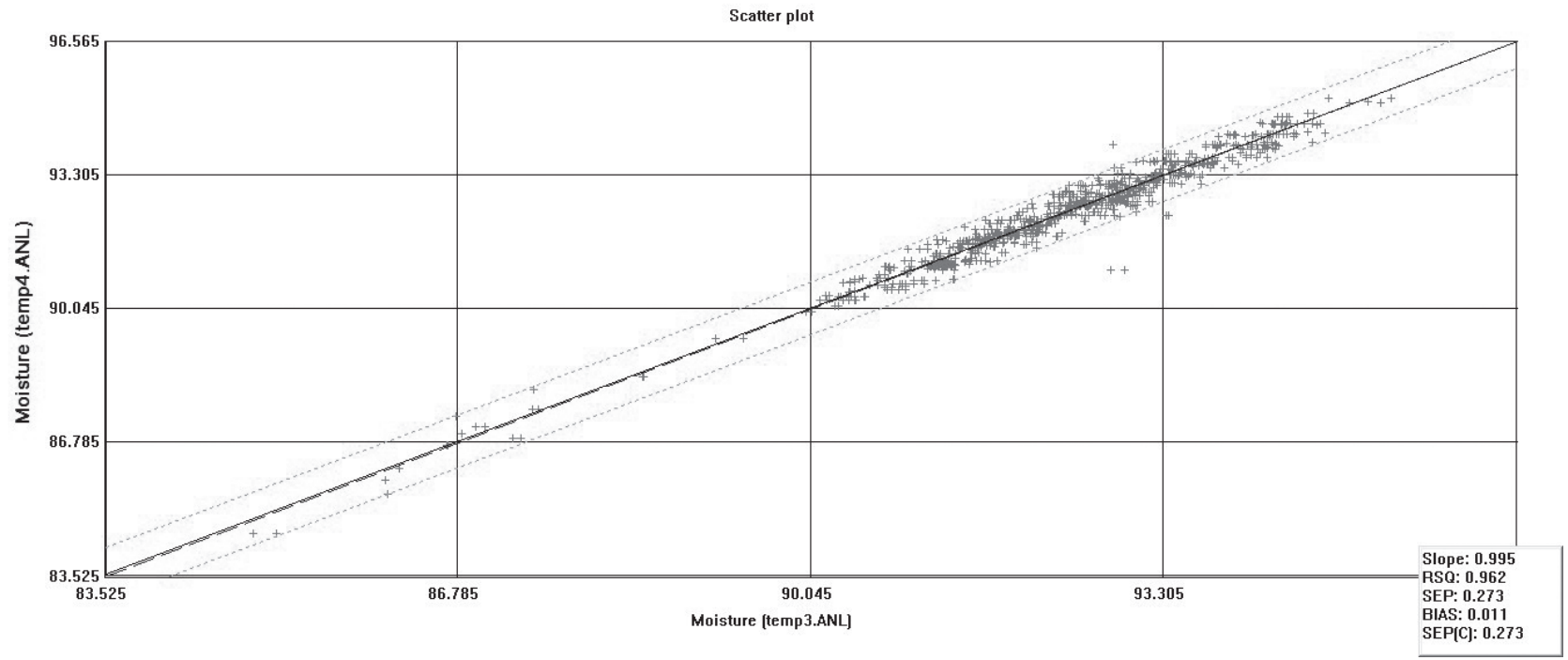

Fig. 8. Scatter plot moisture content press final effluent.

The palm oil industry is a fast growing industry today, but in the processing process, every ton of fresh fruit and fruit can produce liquid waste of around $50 \%$ when compared to the total other waste. Palm oil mill effluent (POME) is a liquid non-toxic waste from the process of producing palm oil derived from condensate and clarification. Fig. 7 shows how we can see the scatter plot of the oil content in the final effluent sample where the slope obtained is 0.999 with the standard error prediction of 0.076 (numbers are coefficient and index without units), with a population number of 1,025. Calibration produces a good slope where the resulting error is also within statistical tolerance limits.

Fig. 8 shows that we can see the scatter plot of water content in final effluent sample with slope 0.995 and prediction error standard 0.273 (numbers are coefficient and index without units), with population number 1,025.

Since the results the checked parameters (FFA, IV, DOBI) are valid and close to the result of extraction, it can be observed that NIR analysis can also be used in refinery processes.

NIR analysis is not a standard method usually utilized in refinery companies, but in quality, analysis can be used as the conventional secondary method so that in its development need to be done calibration and validation [26]. Calibration is done by determining the specific level of the sample using the primary standard method and introduced into the software on the NIR tool, which further developed the regression model [27-28]. The model is based on the relationship between signal intensity and the data from the sample. After the regression model was developed, validation was done by analyzing the sample using the NIR tool and comparing it with the primary standard method [20-21]. The Center for Oil Palm Research (PPKS) has developed NIR techniques to analyze CPO quality, including free fatty acid content, moisture content, carotene content, deterioration of bleachability index (DOBI) and iodine number. The result of calibration model development is obtained by standard calibration errors and the standard of relatively low validation errors and relatively high correlation coefficient $(>0.95)$ $[8,29]$. From the model, the unknown sample quality was analyzed and the value obtained is close to the value obtained by the primary standard method. The determination of CPO quality parameters using NIR can also be done simultaneously, meaning that from one NIR sample we can determine more than one parameter of quality $[26,30]$.

Table 1 is the time comparison of the process of the oil content analysis using the conventional method (extraction), where the conventional method takes a long time from preparation to the calculation of oil content. It can be observed that the conventional method takes 9.5 hours while NIR only takes 5 minutes. It proves that NIR can shorten the analysis time compared to the primary method, and NIR can analyze the samples until data analysis is obtained within \pm 5 minutes, while with the standard method (extraction) takes 9.5 hours. It is considered time efficient since the NIR method cuts up to $99 \%$ time needed for the IV analysis. In addition, the

Table 1. Comparison of primary method to NIR.

\begin{tabular}{|c|c|c|}
\hline Parameter & $\begin{array}{c}\text { Titration } \\
\text { (minutes) }\end{array}$ & $\begin{array}{c}\text { NIR } \\
\text { (minutes) }\end{array}$ \\
\hline Preparation & 30 & 3 \\
\hline Solvent extraction & 360 & 0 \\
\hline Solvent removal & 180 & 0 \\
\hline Cooling and weighing & 60 & 0 \\
\hline Analysis Process & 0 & 2 \\
\hline Total Duration & $570( \pm 9.5$ hours $)$ & 5 \\
\hline
\end{tabular}


utilization NIR does not destroy the sample so that the sample can be returned to the process because it does not contain hazardous chemicals. Since NIR does not use any hazardous and toxic chemicals, it can be concluded that NIR causes a less negative environmental impact compared to the extraction analytical methods since it produced less waste.

In addition to the quality of $\mathrm{CPO}$ and the oil content of the mesocarp in determining the yield potential, PPKS has also identified the loss of oil on sideways in a solid and liquid form using an NIR device. The scatter plot can be seen in Fig. 10. The results obtained show that NIR tools provide data that is not much different from the primary standard method. Thus, the use of NIRs in oil palm mills is beneficial both for CPO quality analysis and even for the analysis of CPO losses at every stage of the process, such as press-fiber, empty length, condensate and sludge. So that the corrective action and improvement of both quality and yield immediately can be done, productivity and performance in palm oil mills continue to increase. Furthermore, capacity-building efforts such as knowledge sharing and practical assistance [31] are needed to engage more on the NIR method.

\section{Oil Loss Calculation of NIR Methods}

The NIR method has been widely used by oil palm processing factories to measure oil losses. This method will help the plant set a standard number of palm oil factories. With this standard oil loss, the calculation process can be done very quickly, resulting in a more accurate value of oil losses due to the value of oil losses that already have a standard. So the factory can see how much oil losses have occurred. This could be an evaluation to an existing system of the factory and a great opportunity to improve based on environmental sustainability principles in the future.

\section{Conclusions}

The use of NIR technology to evaluate the quality of CPO has mostly shown good results and achieved a standard value. Some things to note are that using NIR technology CPO evaluation will take place quickly. This does not require chemical preparation, and because the timing of analysis is fast, of course, and energy efficient despite relatively high equipment prices. From the result of the research, we observed that NIR analysis can shorten the analysis time compared to the primary standard method (extraction), since it cuts up to $99 \%$ of the time needed for the IV analysis. In addition, since NIR does not use any hazardous and toxic chemicals, it can be concluded that NIR causes less negative environmental impact compared to the extraction analytical methods and produces less waste. Based on the advantages observed, the authors support the use of NIR spectroscopy as an alternative method of IV analysis in CPOs refinery companies.

\section{Acknowledgements}

This paper was presented at the $7^{\text {th }}$ Southeast Asian Studies Symposium organized by the School of Environmental Science (SIL), Universitas Indonesia (UI) and the Indonesian Environmental Scientists Association (IESA) in cooperation with the Southeast Asia Project (SEA), University of Oxford on 22 to 24 March 2018 in Jakarta. It was then developed into a research project funded by an international research collaboration grant by Universitas Indonesia 2019 with contract number NKB-1959/UN2.R3.1/ HKP.05.00/2019.

\section{Conflict of Interest}

The authors declare no conflict of interest.

\section{References}

1. Central Bureau of Statistics of Republic of Indonesia, 2012.

2. Presidential Regulation 32/2011 regarding Masterplan Acceleration and Expansion of Indonesian Economic Development.

3. Government Regulation of The Republic of Indonesia 74/2001 regarding The Management of Hazardous and Toxic Materials.

4. WIESNER K., FUCHS K., GIGLER A., PASTUSIAK R. Trends in Near Infrared Spectroscopy and Multivariate Data Analysis from an Industrial Perspective. Procedia Engineering, 87, 867, 2014.

5. MOHAMED E.S., SALEH A.M., BELAL A.B., GAD A. Application of near-infrared reflectance for quantitative assessment of soil properties. The Egyptian Journal of Remote Sensing and Space Sciences, 21, 1, 2017.

6. SIESLER H. Vibrational Spectroscopy. Reference Module in Materials Science and Materials Engineering, 2016.

7. LI Y., ALTANER C.M. Effects of Variable Selection and Processing Of NIR And ATR-IR Spectra on The Prediction of Extractive Content in Eucalyptus Bosistoana Heartwood”. Spectrochimica Acta Part A: Molecular and Biomolecular Spectroscopy, 213, 111, 2019.

8. LANDAU S., GLASSER T., DVASH L. Monitoring nutrition in small ruminants with the aid of near infrared reflectance spectroscopy (NIRS) technology: A review. Small Ruminant Research, 61, 1, 2006.

9. GALASSO H.L., CALLIER M.D., BASTIANELLI D., BLANCHETON J.-P., and ALIAUME C. The potential of near infrared spectroscopy (NIRS) to measure the chemical composition of aquaculture solid waste. Aquaculture, 476, 134, 2017.

10. MANAF F.Y.A., CHUNG A.Y.K., YASIR M.Z. Premium oil segregation using Near-Infrared (NIR) online system. Feature Article of Palm Oil Engineering Bulletin 122, 2010. 
11. CEN H., HE Y. Theory and Application of Near Infrared Reflectance Spectroscopy in Determination of Food Quality. Trends in Food Science Technology, 18, 72, 2007.

12. LUYPAERT J., MASSART D., VANDER HEYDEN Y. Near-infrared spectroscopy applications in pharmaceutical analysis. Talanta, 72, 865, 2007.

13. DE GIROLAMO A., VON HOLST C., CORTESE M., CERVELLIERI S., PASCALE M., LONGOBARDI F., CATUCCI L., PORRICELLI A., LIPPOLIS V. Rapid screening of ochratoxin A in wheat by infrared spectroscopy. Food Chemistry, 282, 95, 2019.

14. CORONEL-REYES J, RAMIREZ-MORALES I, FERNANDEZ-BLANCO E, RIVERO D, and PAZOS A. Determination of egg storage time at room temperature using a low-cost NIR spectrometer and machine learning techniques. Computers and Electronics in Agriculture, 145, 1, 2017.

15. CHAVAN R.B., BHARGAVI N., LODAGEKAR A., SHASTRI N.R. Near-infra red spectroscopy: a tool for solid state characterization. Drug Discovery Today, 22, 7, 2017.

16. LIN H., MARJANOVIC O., LENNOX B., SHAMEKH A. Application of Near-infrared Spectroscopy in Batch Process Control. IFAC Proceedings, 42, 750, 2009.

17. AÏT KADDOUR A., CUQ B. Dynamic NIR spectroscopy to monitor wheat product processing: a short review. American Journal of Food Technology, 6, 186, 2011.

18. PHETPAN K., UDOMPETAIKUL V., SIRISOMBOON P. In-Line Near Infrared Spectroscopy for The Prediction of Moisture Content In The Tapioca Starch Drying Process. Powder Technology, 345, 608, 2019.

19. O'SHEA M.G., STAUNTON S.P., SLUPECKI P. Implementation of on-line near infrared (NIR) technologies for the analysis of cane, bagasse and raw sugar in sugar factories to improve performance. International Sugar Journal, 113, 879, 2011.

20. BURNS D.A., CIURCZAK E.W. Handbook of nearinfrared analysis, $3^{\text {rd }}$ ed.; CRC Press Taylor \& Francis Group: New York, USA, 2006.

21. PIERNA J.F., MANLEY M., DARDENNE P., DOWNEY G., BAETEN V. Spectroscopic Technique: Fourier Transform (FT) Near-Infrared Spectroscopy (NIR) and Microscopy (NIRM). Modern Techniques for Food Authentication, 103, 2018.
22. LICHI S. NIR for real-time monitoring of biogas process. Journal of Bioresource Technology, 247, 1249, 2017.

23. PANDEY M.M. Non-destructive evaluation of food quality: theory and practice; New York, USA: Springer Heidelberg Dordrecht, 2010.

24. ZHANG W., LI N., FENG Y., SU S., LI T., LIANG B. A unique quantitative method of acid value of edible oils and studying the impact of heating on edible oils by UV-Vis spectrometry. Food Chemistry, 185, 326, 2015.

25. MAJID R., MOHAMMAD A., MAY C. Properties of Residual Palm Pressed Fibre Oil. Jurnal of Palm Oil Research, 24, 1310, 2012.

26. DYMINSKA L., CALIK M., ALBEGAR A.M.M., ZAJAC A., KOSTYN K., LORENC J., HANUZA J. Quantitative determination of the iodine values of unsaturated plant oils using infrared and Raman Spectroscopy methods. International Journal of Food Properties, 20, 3, 2016.

27. GRANGE S.K., LEWIS A.C., CARSLAW D.C. Source apportionment advances using polar plots of bivariate correlation and regression statistics. Atmospheric Environment, 145, 128, 2016

28. PELEG Y., SHEFER S., ANAVY L., CHUDNOVSKY A., ISRAEL A., GOLBERG A., YAKHINI Z. Sparse NIR optimization method (SNIRO) to quantify analyte composition with visible (VIS)/near infrared (NIR) spectroscopy $(350 \mathrm{~nm}-2500 \mathrm{~nm})$. Analytica Chimica Acta, 1051, 32, 2019.

29. ZHOU X.-P., HUANG X.-C. Reliability analysis of slopes using UD-based response surface methods combined with LASSO. Engineering Geology, 233, 111, 2017.

30. MABOOD F., BOQUE R., HAMAED A., JABEEN F., AL-HARRASI A., HUSSAIN J., ALAMERI S., ALBROUMI M., NABHANI M.M.O.A., NAUREEN Z., RAWAHI M.A., FUTAISI F.A.S.A. Near-Infrared Spectroscopy Coupled with Multivariate Methods for the Characterization of Ethanol Adulteration in Premium 91 Gasoline. Energy Fuels, 31, 7591, 2017.

31. SURATIN A., KARUNIASA M., UTOMO S.W. Is Sustainable Oil Palm Production Possible for Smallholders? Journal of Environmental Science and Sustainable Development, 1 (1), 25, 2018. 
